\title{
Aprendendo a clínica do sofrimento social: narrativas do internato na Atenção Primária à Saúde
}

\author{
Learning the clinic of social suffering: \\ narratives of Internship in Primary Health Care
}

Felipe Monte Cardoso (https://orcid.org/0000-0001-9898-6389) 1,2

Gastão Wagner de Sousa Campos (https://orcid.org/0000-0001-5195-0215) ${ }^{1}$
${ }^{1}$ Universidade Estadual de Campinas, Faculdade de Ciências Médicas. R. Vital Brasil 50, Cidade Universitária. 13083-888 Campinas SP Brasil. felipemontecardoso@ gmail.com

${ }^{2}$ Faculdade de Medicina, Universidade Federal do Rio de Janeiro. Rio de Janeiro RJ Brasil.

\begin{abstract}
In Brazil, the mismatch between medical education and care needs in primary health care, especially for the most vulnerable populations, required changes in the National Curriculum Guidelines of the Medical School, with an increased workload of the internship in PHC. This work is exploratory, qualitative research, which investigated documents of the formative evaluation of the Integrated Internship in Family and Community Medicine and Mental Health of the Federal University of Rio de Janeiro, which serves vulnerable populations in the city of Rio de Janeiro. The documents produced by 55 students were analyzed, and dialectical hermeneutics was used as a method of analysis. The investigation showed different levels of sensitivity to social distress experienced by users of Family Clinics during the 22 weeks of internship. The narratives were grouped into five axes: highlighting the Medicine-society split; extreme vulnerability and health; daily structural violence and health; health service as a resource or intruder; territory as the power of life. The internship contributed to improve clinical views focused on users' needs, and further studies are required to evaluate the effective incorporation of these competencies into professional practice.

Key words Medical education, Internship and residency, Primary health care
\end{abstract}

Resumo No Brasil, o descompasso entre a formação médica e as necessidades assistenciais na atenção primária à saúde, em especial para as populações mais vulneráveis, demandou mudanças nas Diretrizes Curriculares Nacionais do curso de Medicina, com ampliação da carga horária do Internato na APS. Este trabalho é uma pesquisa qualitativa exploratória, que investigou documentos da avaliação formativa do Internato Integrado em Medicina de Família e Comunidade e Saúde Mental da Universidade Federal do Rio de Janeiro, que atendem populações vulneráveis no município do Rio de Janeiro. Ao todo, foram analisados documentos produzidos por 55 estudantes e utilizou-se a hermenêutica dialética como método de análise. A investigação apontou distintos graus de sensibilidade ao sofrimento social experimentado por usuários de Clínicas da Família, ao longo das 22 semanas de estágio. As narrativas foram agrupadas em 5 eixos: tensionando a cisão medicina/sociedade; vulnerabilidade extrema e saúde; violência estrutural cotidiana e saúde; serviço de saúde como recurso ou intruso; território como potência de vida. O internato contribuiu para aprimorar visões clínicas centradas nas necessidades dos usuários, sendo necessários estudos adicionais para avaliar a incorporação efetiva destas competências à prática profissional.

Palavras-chave Educação médica, Internato e residência, Atenção Primária à Saúde 


\section{Introdução}

De acordo com a Declaração de Alma-Ata, sistemas baseados na Atenção Primária à Saúde (APS) são essenciais para o desenvolvimento e a justiça social ${ }^{1}$. No Brasil, a expansão da APS explicitou as dificuldades de provimento de médicos com competências específicas para assistir a populações de maior vulnerabilidade social ${ }^{2}$. $\mathrm{O}$ aprendizado da medicina nestes contextos é desafiante ${ }^{3,4}$ e se soma à persistência de imensas disparidades sociais na distribuição de médicos e das faculdades de medicina no Brasil ${ }^{5}$. Para superar estes problemas, políticas públicas têm buscado induzir ênfase na formação em cenários comunitários, como consta nas Diretrizes Curriculares Nacionais (DCN) para o curso de Medicina ${ }^{6}$. Apesar disto, existem muitas resistências para a expansão e a qualificação da formação médica na $\mathrm{APS}^{7}$.

Mesmo assim, existe tendência de aumento da participação de serviços comunitários na formação das profissões de saúde ${ }^{8,9}$, o que colocou a centralidade do contexto nos currículos ${ }^{10}$. Estes novos desafios para a educação médica, antes vistos como processo meramente individual ou centrado na interação professor-aluno, fizeram com que fatores como o papel da equipe de saúde ${ }^{11}$, de pacientes $^{12}$ e das comunidades ${ }^{10}$ ganhassem projeção. Ademais, a ênfase no hospital pode prejudicar a aquisição de competências e a formação da identidade profissional ${ }^{13}$.

Além da centralidade no hospital, a hegemonia do paradigma biomédico nas escolas médicas concorre para a inadequação do perfil dos médicos formados no Brasil. Uma visão mecanicista das biociências na prática médica promove alienação do médico ${ }^{14}$, distorções do cuidado em saúde ${ }^{15}$ e formas autoritárias nas relações de poder entre médicos e usuários ${ }^{16}$. Propostas de superação do paradigma biomédico passam pela recuperação da dimensão cuidadora das práticas de saúde ${ }^{17}$, da dimensão relacional do cuidado ${ }^{18} \mathrm{e}$ pelo resgate da centralidade do sujeito portador de sofrimento ${ }^{15}$. A Medicina de Família e Comunidade (MFC) preconiza a centralidade das práticas na pessoa que sofre, ao invés de subordiná -las a um corpo de conhecimento abstraído em grupo de doenças ou técnicas específicas ${ }^{19}$. A experiência de adoecer e o reconhecimento do contexto (psíquico, familiar, ocupacional e social) da pessoa são fundamentais para a perspectiva epistemológica da especialidade.

O processo de formação médica pode ser entendido como um treino do olhar ou da sensibi- lidade $^{20}$, que implica na perspectiva de superação do paradigma biomédico, por compreender o sofrimento individual como inseparável do social ${ }^{21}$ e, em especial, como o sofrimento social é agravado pela violência estrutural ${ }^{22}$. A Competência Cultural é um dos atributos da $\mathrm{APS}^{23}$ que aborda estas questões, embora haja críticas a visões reducionistas do conceito ${ }^{24}$. A Educação Baseada em Competências ${ }^{25}$ também sofre críticas por utilizar o conceito da competência como desdobramento natural do progresso científico, sem entendê-las como construtos sócio-históricos permeados por relações de poder ${ }^{11}$.

O reexame crítico do aprendizado da competência cultural pode ser baseado em duas abordagens que valorizam a singularidade contextual e o aprendizado prático e coletivo: a Teoria da Atividade Histórico Cultural, que busca apreender a complexidade social e cultural intrínsecas ao trabalho em saúde, focando no aprendizado clínico situado nas contradições do trabalho em saúde, ao inserir o estudante no meio social onde vive e aprende ${ }^{26}$; e a Teoria da Aprendizagem Sociocultural, que entende o aprendizado como processo sociocultural, em que estudantes se tornam membros de sua comunidade profissional, legitimados pela escola médica e pelo serviço de saúde. A produção e a reprodução de conhecimentos, habilidades e atitudes se dá em processo dialético, entre aprendizes, docentes e profissionais de saúde ${ }^{27}$.

Este trabalho investiga a relação destas questões com a introdução de estágios longos de Internato na Atenção Primária à Saúde. Trata-se de pesquisa qualitativa exploratória que estudou documentos de avaliação formativa do Internato Integrado (MFC) e Saúde Mental da UFRJ/ Campus Fundão. $\mathrm{O}$ enfoque está na experiência dos internos em assistir ao sofrimento social: a vivência corporificada da dor e das formas de sofrer nas relações sociais; os modelos culturais e morais que condicionam os sofrimentos dos sujeitos; e, por fim, os discursos pelos quais as instituições (como a ciência médica) classificam e legitimam as distintas experiências de sofrimento $^{28}$.

\section{Metodologia}

Trata-se de um estudo documental qualitativo exploratório, que buscou compreender a influência dos aspectos contextuais no aprendizado dos internos de medicina da UFRJ na rede de (APS) do Rio de Janeiro. Este estudo é parte da tese de 
doutorado de um dos autores. Estudou-se banco de dados com material de avaliação formativa da disciplina coletado no ano de 2017, com alunos do $10^{\circ}$ e $11^{\circ}$ períodos. A disciplina dura $22 \mathrm{se}-$ manas e ocorre em 13 Clínicas da Família (Unidades de Atenção Primária do Rio de Janeiro) e, opcionalmente, em Centros de Atenção Psicossocial (CAPS) e equipes de Consultório na Rua $(\mathrm{CNAR})^{29}$. Estes equipamentos atendem majoritariamente populações de alta vulnerabilidade. Este formato de internato foi possível graças à Reforma da APS carioca ${ }^{30}$ e nele se buscam desenvolver competências ligadas à MFC. Alguns dos objetivos estão listados no Quadro 1.

Dentre as metodologias de avaliação do estágio, se encontram os diários de campo e os relatórios finais; e os grupos focais. Os diários de campo e os relatórios finais são métodos de avaliação formativa, baseados na escrita reflexiva de casos atendidos e situações vivenciadas nos serviços, à luz da Medicina Centrada na Pessoa ${ }^{19}$, dos atributos da APS e dos princípios do SUS. Os primeiros são redigidos semanalmente por todos os internos e enviados para supervisores da universidade, e há feedback em supervisões semanais; os segundos são entregues ao fim do estágio.

Os Grupos Focais foram introduzidos em 2017 como ferramenta de avaliação das necessidades de aprimoramento pedagógico da disciplina $^{31}$, de forma a privilegiar o diálogo entre os estudantes. Eles foram feitos no começo e no final da rodada, para acessar a experiência de aprendizado dos estudantes com pacientes, e sua condução e registro, com gravação de áudio, contou com professores do internato que têm experiência em pesquisa qualitativa. Os áudios passaram então ao banco de dados da disciplina. $\mathrm{Na}$ investigação foram utilizados os grupos focais cuja transcrição apresentava boa qualidade técnica: foram incluídas as transcrições em que participaram 55 internos ao todo. O material analisado se refere a cinco grupos focais no começo e a outros cinco no final da rodada. Nos Grupos Focais, os internos foram provocados pelas duas perguntas $O$ que vocês acabaram de ver? e $O$ que vocês acham que aconteceu?, após a exibição de vídeos com situações comuns na APS, relacionadas ao cuidado de pacientes e de famílias de grande vulnerabilidade e complexidade. Os professores interferiram o mínimo possível no desenrolar dos grupos.

A análise de dados seguiu a abordagem hermenêutica dialética ${ }^{32}$, que busca compreender o outro através da comunicação, especialmente pela compreensão de textos - neste caso, as narrativas produzidas pelos internos. Alteridade, entendimento e mal-entendido são possibilidades universais no campo científico e no mundo da vida. Trata-se de procedimento que busca o contextual como expressão da totalidade, pela revelação do que "o outro" coloca como verdade: em síntese, compreender implica a possibilidade de estabelecer relações e extrair conclusões em todas as direções. Mas compreender acaba sempre sendo compreender-se ${ }^{32}$. A análise, descrita adiante, está ilustrada na Figura 1.

Para a análise, foram selecionados 20 diários de campo/relatórios finais de 4 clínicas da família e a transcrição de 13 grupos focais, que incluiu estudantes de todos os campos de estágio.

Quadro 1. Objetivos selecionados do internato.

Quadro 1. Objetivos selecionados do internato.
\begin{tabular}{|l} 
Objetivos selecionados do internato \\
\hline $\begin{array}{l}\text { Ampliar cenário de práticas para o ensino da medicina, segundo orientação das DCN, constituindo estágio } \\
\text { obrigatório na área da Atenção Primária à Saúde- Estratégia Saúde da Família }\end{array}$ \\
\hline $\begin{array}{l}\text { Desenvolver conhecimentos, habilidades e atitudes para a prática da medicina de família, com abordagem } \\
\text { integral e ação interdisciplinar em consonância com os princípios do SUS }\end{array}$ \\
\hline $\begin{array}{l}\text { Realizar ações de prevenção, diagnóstico e tratamento dos problemas de saúde do indivíduo, família e } \\
\text { comunidade, considerando os ciclos de vida, as diferentes realidades sociais e ênfase aos transtornos mentais }\end{array}$ \\
\hline Fazer visitas domiciliares para orientações clinicas, promoção da saúde, prevenção e rastreamento de doenças \\
\hline $\begin{array}{l}\text { Realizar atividades coletivas com grupos sociais, famílias e comunidades, com vista a ações de proteção e } \\
\text { promoção da saúde }\end{array}$ \\
\hline $\begin{array}{l}\text { Atuar de forma interdisciplinar na ESF, reconhecendo a capacidade e responsabilidades da rede local e membros } \\
\text { da equipe }\end{array}$ \\
\hline $\begin{array}{l}\text { Reconhecer o sofrimento psíquico presente em muitos usuários, sendo caparz de contextualizá-lo e acolhê-lo } \\
\text { dentro do âmbito da consulta médica }\end{array}$
\end{tabular}




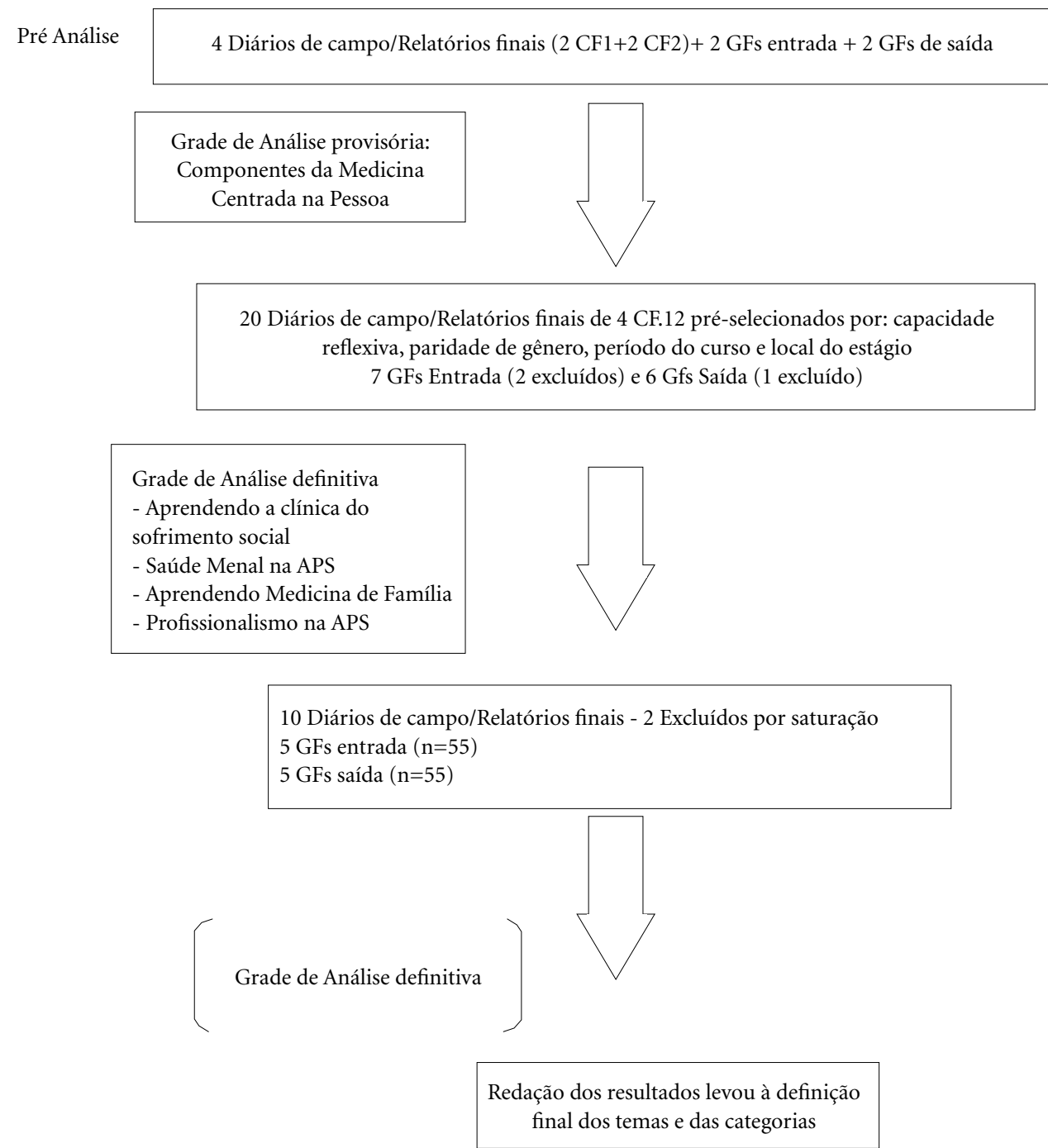

Figura 1. Processo de análise dos dados.

Fonte: Autores, 2019.

Ao todo, 12 diários de campo/relatórios finais foram escolhidos para a análise por critérios de boa capacidade reflexiva, paridade de gênero e de semestre no curso, equilíbrio entre os campos de estágio. Dois foram excluídos por saturação. Três transcrições de grupos focais foram excluídas por má qualidade técnica. A grade definitiva foi aplicada sobre esta amostra e as grandes categorias foram mantidas, com pequena reelaboração dos temas.

A análise destes textos foi realizada com base em quatro grandes categorias: Aprendendo a clínica do Sofrimento Social, Aprendendo a Medicina de Família e Comunidade, Aprendendo Saúde Mental na APS e Formação da Identidade Profissional fora do hospital. A produção deste trabalho é atravessada pelo olhar de um dos autores, professor universitário e médico de família da rede do SUS carioca, que busca construir pontes nestes campos de trabalho e formação que supere os abismos entre o mundo dos futuros médicos e o dos usuários do SUS. Os temas que emergiram nas narrativas foram analisados pela perspectiva de crítica à hegemonia biomédica $\mathrm{e}$ 
pelo enfoque da competência cultural. Todos os nomes de pessoas e locais relatados são fictícios. O trabalho foi aprovado no Comitê de Ética em Pesquisa do Instituto de Psiquiatria da UFRJ.

\section{Resultados/discussão}

Os temas encontrados na análise dos textos foram: Tensionando a cisão medicina/sociedade; Vulnerabilidade extrema; Violência estrutural cotidiana; Serviço de saúde: Recurso ou intruso?; Território como potência de vida. Abaixo, se encontra a discussão destes resultados à luz da metodologia utilizada.

\section{Tensionando a cisão medicina/sociedade}

No universo dos primeiros relatos do estágio, os termos clínico, biológico e técnico aparecem em oposição à social e humano. Representaram uma visão de mundo cindida que, ao separar medicina de sociedade, dificilmente concordaria que toda medicina é social ${ }^{16}$. Desde o começo do estágio, a necessidade de classificar os sintomas de acordo com o método biomédico se chocou com a percepção da importância dos componentes psicossociais para o manejo do sofrimento percebido nos vídeos, em especial quando debatem os limites de uso de medicação psiquiátrica para casos em que o contexto é decisivo para o tratamento. Diante da narrativa do ator-paciente psicótico, os internos se questionam sobre a epistemologia biomédica e sua eficácia:

[Como] esquecer completamente esse viés mais social, a influência da sociedade sobre o desenvolvimento ou não de um transtorno? (Estudante feminina, GF 4)

As histórias de vida de usuários, seu contexto sociocultural, a experiência singular de sofrimento adoecimento foram entrando aos poucos nas narrativas, convivendo lado a lado com notas semiotécnicas e guidelines. A rede de pacientes atendidos, equipe, artefatos e recursos do território tecida pelos alunos no cotidiano do estágio foi determinante para o equilíbrio entre a doença, a experiência do adoecimento e o contexto dos usuários nos relatos dos internos. Visões do processo de saúde e doença passaram a levar em conta a determinação social: Há um processo de evolução (na atenção primária, em especial) na qual se pensa a saúde e a doença como um gradiente que perpassa as classes socioeconômicas. (Raul, RF)

Com o avançar do estágio, foi comum referir-se às práticas vivenciadas como novo tipo de medicina ou medicina humanizada, remontando à epistemologia monista da $\mathrm{MFC}^{33}$. Ainda assim, a cisão medicina/sociedade persistiu em algumas narrativas. Em um dos casos, ela foi mediada pelos desafios concretos da clínica e não por uma visão pré-concebida da prática. Mas, de forma geral, as tensões teóricas e práticas dos relatos fizeram emergir a dicotomia medicina/sociedade como anomalia do paradigma biomédico ${ }^{19}$

Quando temos que, além da sua história pessoal, também investigar a história de sua doença, esta demanda de tempo cresce enormemente (William, S14).

A gente esquece, mas a medicina é uma ciência social, não é uma ciência exata (Estudante masculino, GF10)

\section{Vulnerabilidade extrema}

Pudemos observar no item anterior que a experiência vivida no estágio foi como um abrir de olhos para aspectos essenciais à clínica na APS e que são inexistentes ou marginais no currículo. Ao entender a formação médica como uma educação da sensibilidade - ou do olhar - para os diversos aspectos do adoecimento ${ }^{34}$, as narrativas com foco no sofrimento difuso e intenso dos pacientes mais vulneráveis ganharam relevo no olhar dos internos, desafiando a percepção unicausal ou mesmo biomédica do adoecimento. Dois conjuntos de narrativas se destacaram: do território como perpetuador de más condições de saúde e de acesso aos serviços, e o das vidas adoecidas nestes contextos. O primeiro aflora das incursões pelos territórios durantes as Visitas Domiciliares, os estágios de CAPS e o Consultório na Rua, e, em menor medida, pelo deslocamento dos internos. Possível reflexo do corte elitizado de parte expressiva dos estudantes, muitos se espantaram como a geografia das favelas agrava as dificuldades de acesso aos serviços públicos. As impressões sobre a relação do território e das condições de vida com o adoecimento, mais que saltar aos olhos dos internos, também revelam entendimentos diversos sobre este processo. Para alguns, há uma explicação macrossocial, engajada: a sociedade deve ser subvertida para garantir condições mínimas de saúde. Outros enfatizaram, em tônica de culpa, as responsabilidades individuais ou familiares. Curiosamente, estes olhares, quase antagônicos, têm um denominador comum: o foco são os problemas e não as potências do território. Talvez persista certo ethos do diagnóstico, ainda que de diagnósticos socialmente referenciados. 
Nos encontros com os usuários em extrema vulnerabilidade, o sofrimento dos estudantes transbordou. A complexidade das situações e os densos fluxos de afetos colocaram em xeque o arsenal biomédico e abriram caminho para a incerteza. Relatos como o da usuária enlutada pelo falecimento da filha por lúpus, não aguentava mais cuidar do marido em estado terminal, de quem sofreu violência por décadas, humanizam estudante e paciente, criando uma comunhão na dor e no cuidado e, por um breve momento, equiparou:

Durante diversos momentos da nossa conversa ela chorou e me questionou como poderia fazer para dar fim aquela dor que tanto a afligia. Eu não tinha respostas e, talvez, nunca terei. (Juliana, S8)

Ao imergir no cotidiano das pessoas mais vulneráveis, a quase completa falta de referência à rede intersetorial no manejo destes casos revelou o profundo desconhecimento destes recursos para o cuidado de pessoas vulneráveis. Mesmo contando com equipes de saúde mental de referência, apenas um estudante fez referência aos equipamentos da Assistência Social, o que não deixa de refletir ainda a força do modelo biomédico e a forma da comunidade de práticas da APS no contexto do Rio ${ }^{35}$.

\section{Violência estrutural cotidiana}

A degradação das políticas de segurança pública na cidade do Rio de Janeiro fez-se sentir em 2017 com o aumento do registro de assaltos e tiroteios. Esta mudança qualitativa impactou diretamente o cotidiano da rede de APS, cuja implementação se deu no contexto da aposta em Unidades de Polícia Pacificadoras como política pública situada no território, para o combate aos chamados mercados ilegais, buscando superar a lógica de confronto.

A crescente de violência foi captada pelo cotidiano do trabalho nas unidades, no sofrimento dos pacientes e na vida social em geral, pôde-se perceber o quanto a violência estrutural ${ }^{22,36}$ adensa os processos de sofrimento e cuidado na rede. Por vezes, ela foi percebida pela relação conturbada do serviço com usuários:

[...] como você pode esperar que as pessoas vão ter uma reação calma, tranquila e pacífica enquanto o que elas aprenderam na vida não é ser calma, tranquila e pacifica? (EM, GF 6)

A violência armada, por um lado, faz parte do cotidiano dos serviços e dos territórios. Por outro, os riscos inerentes a este cenário levaram muitas clínicas a adotar a classificação de risco
Acesso Mais Seguro ${ }^{37}$, que monitora possíveis focos de conflitos e, com base nisso, decide-se se há condições para funcionamento ou se a clínica deve ser evacuada. Os relatos sobre estas ocasiões são muito significativos. A tensão que o risco iminente de conflito armado provocou nos alunos evocou cumplicidade com a comunidade, resignação ou ganas de desistir da cidade e mesmo medo de morrer.

Para extremo azar de minha colega interna, [...] ela viu um dos envolvidos no confronto portando uma arma, bem do lado dela, correndo imediatamente após os disparos. Ficou desnorteada, desesperou-se e caiu no choro. (Jean, S18)

Possivelmente refletindo um cenário de mudança no ambiente universitário, em que proliferam coletivos em defesa dos direitos de mulheres, LGBTs e negros, uma minoria ressaltou situações vividas por grupos particularmente vulneráveis: tragédias produziram com frequência solidariedade, mas por vezes sofrimento e conformismo nos internos. Ao relatar histórias com muitas camadas de violência, as narrativas tiveram uma dupla função: testemunharam o papel essencial das clínicas da família e do SUS na assistência ao sofrimento da violência estrutural e acenaram e legitimaram o sofrimento social como questão relevante da prática médica:

[...] ao cuidar de sua mãe [que sofre de demência] e impedir que a mesma fosse para rua no auge do conflito, acabou sendo atingida por uma bala perdida no ombro. Contou o desespero do momento, sem saber se cuidava do seu ombro ou da mãe que queria ir varrer a calçada. (Carolina, S5)

Além da violência diária do morro, da violência policial e do tráfico, essa usuária teve que lidar com a violência homofóbica e a marginalização da profissão do sexo. (Jean, S14)

[...] uma paciente que tava sofrendo muito porque o filho [...] comprou droga de outra facção e assassinaram ele, e impediram ela de sofrer no morro. [...] então ela ia na clínica para chorar e conversar sobre seu luto. (EF, GF6)

\section{Serviço de saúde: recurso ou intruso?}

Embora as Visitas Domiciliares sejam parte do cotidiano do trabalho das equipes, a maioria dos internos as conheciam pouco. Ao adentrar o território acompanhando ACSs, muitos dos enfermeiros e médicos as perceberam como ferramenta indispensável para acessar questões que não aparecem nos settings tradicionais:

[...] dentro do consultório você explica [...] e o paciente sai como se ele fosse fazer aquilo. Você 
chega na casa dele e não é nada do que ele diz que entendeu, ele não tá fazendo nada daquilo. (EF, GF10)

A tônica de surpresa e mesmo de fascínio pela potência da visita para facilitar a compreensão do contexto, da adesão ao tratamento, marca uma diferença substantiva do cenário hospitalar. Por outro lado, a presença das equipes no território, por vezes de forma ostensiva, fez emergir incômodos nos relatos com uma certa postura invasiva:

A situação de Gabriel foi informada à equipe pela ACS da área e nós começamos a ir lá sem qualquer solicitação ou convite. Temos invadido a casa deles, o quarto dele. Qual é o limite do cuidado nesses casos?(Jean, S13)

Ao contrário do hospital, onde a soberania da medicina sobre os corpos dos pacientes é praticamente inquestionável, a presença não solicitada da equipe de saúde em uma casa explicita a visão da medicina como ferramenta de controle molecular dos corpos ${ }^{16,38}$. A empatia dos alunos que não concebem uma ação tão intrusiva em seus próprios lares explicita o choque entre as visões de privacidade e de intimidade nos diversos estratos da sociedade, como relatam os ACSs nas visitas em territórios de "morro e asfalto". A tensão entre ser recurso e intruso apareceu, em muitas narrativas, passível de solução pelo caminho do encontro dos internos no território e no lar de seus pacientes. $\mathrm{O}$ respeito ao modo vida das pessoas foi ressaltado como requisito para a construção de vínculo e a eficácia terapêutica:

[...] a gente conseguiu ir na casa dele... a gente foi, sentou e conversou com ele, falando 'a gente quer te ajudar, a gente não vai falar mal de você.' E uma semana depois, ele mesmo sozinho apareceu e até uma tia dele ficou 'nossa, o que tá acontecendo?'.(EF, GF10)

\section{Território como potência de vida}

Nas narrativas predominaram as adversidades do cuidado com populações vulneráveis. Ao perceberem sua prática clínica saturada de sofrimento social de grande magnitude, vieram à tona limites e fragilidades do cuidado com as classes populares. Em algumas narrativas, porém, a vida respondeu com sua presença viva. Esta vibração emergiu de situações em que tudo na comunidade fala, nas palavras de Nina. Ou da catarse de uma equipe, que, tendo passado por território repleto de pessoas armadas, retorna de visita a uma paciente em fim de vida, que, apesar disso, planejava sua festa de aniversário:
[...] nossa ACS desatou a chorar, pois se lembrou de um caso semelhante que aconteceu com sua amiga. Todas nós começamos a chorar no meio da rua. Nos abraçamos. Subimos a rua rindo e chorando ao mesmo tempo, refletindo acerca do momento que passamos lá, do quanto aprendemos em tão pouco tempo. (Juliana, S2)

Práticas de solidariedade, como vizinhos que se ajudam após cirurgias e internações, não escaparam à observação da interna Leila. Em outra ocasião de descobertas, foi à Quinta da Boa Vista, ponto de lazer dos cariocas em que ela redescobriu a própria infância. $\mathrm{Na}$ visita ao Museu Nacional, os "loucos" do CAPS se tornam cidadãos plenos de saberes e curiosidades. Ao perceber o papel terapêutico da circulação pela cidade, experimentou a clínica peripatética ${ }^{39}$ onde hoje são escombros:

Eu só tinha ido lá quando era bem nova, então achei legal poder ir de novo. [...] foi interessante notar como coisas diferentes chamavam a atenção de cada um e como eles têm conhecimentos escondidos sobre algumas coisas aleatórias. (S4)

Nem sempre houve êxitos. Depois de fracassar em propor um grupo educativo, Lucas reflete, após ouvir a comunidade, que Pela experiência negativa que tivemos na realização do local [...], decidimos mudar o local do grupo para a quadra, ao lado da Associação de Moradores”(S7). Marília - vítima de grave episódio de violência armada em uma comunidade poucos meses antes - narra um lampejo de visão cidadã de alguém externa à favela, quando novamente a clínica foi fechada:

É uma sensação muito ruim ver aquelas portas fechadas e o desespero disfarçado que se instala nas pessoas. [...] fui embora, mais uma vez aflita, pensando nas pessoas que moram ali. (S10)

Nos momentos mais mágicos do cuidado, houve epifanias. Em certa ocasião, Nina acompanhava a equipe do CNAR, que perambulava de carro em um bairro distante à procura de uma usuária perdida, e o ACS a reconhece:

Um homem, que não tinha nenhum grau de parentesco com uma pessoa negra franzina de casaco de costas no meio de uma rua, sabia exatamente quem era ela! Como assim?! Meus olhos se enchiam de lágrimas enquanto aquele agente comunitário negro descia desesperado da van no meio da rua para envolvê-la com seu casaco e abraço. (S15)

\section{Considerações finais}

Este trabalho pôde estudar a narrativa dos internos sobre a experiência vivida em seu processo 
de aprendizado. Ao vivenciar situações comuns da Atenção Primária nos consultórios e no território, puderam aprimorar sua sensibilidade para muitas formas de sofrimento "não classificáveis" pelo cânone da biomedicina, mas vívidas, saturadas pela violência - e pela potência - dos territórios e pela vulnerabilidade social. Estes achados são relevantes por explicitar como os estudantes se inseriram no cuidado a estas populações e puderam experimentar graus elevados de responsabilização em um momento crucial da formação de sua identidade profissional. Não há, ao menos nos últimos dez anos, estudos brasileiros que enfoquem o aprendizado de competências culturais com ênfase no sofrimento psicossocial no período do internato.

Ao refletir sobre situações complexas, os estudantes puderam experienciar práticas centradas nas pessoas que buscavam atendimento, sob supervisão dos professores da universidade e dos profissionais dos serviços, e produzir sentidos eficácia, realização, frustração, crítica - no seu aprendizado clínico. A transição da visão biomédica para outra ampliada e mais integral da prática médica não foi unívoca. Houve persistência da dicotomia medicina/sociedade para alguns, ocorreu uma única menção à rede intersetorial, enquanto que a sensibilidade ao sofrimento de grupos mais vulneráveis foi minoritária. Isto indica a necessidade de se aplicar métodos de ensino e de avaliação mais homogêneos ao longo do estágio, de forma a garantir aprendizado mínimo das competências culturais.
Outro ponto a ser ressaltado é o papel da equipe: médicos preceptores e residentes, enfermeiros, ACSs e gerentes apareceram nas narrativas com modelos positivos e negativos, capazes de inspirar práticas clínicas eficazes e posturas profissionais, situadas nos contextos daquelas populações. Este modo de aprender a tornar-se médico é fundamental no cenário de grandes transformações das práticas em saúde, que exigem sólidas competências para trabalho coletivo ${ }^{11}$. Por outro lado, não há garantia de que a sensibilização para o sofrimento social esteja na medida das necessidades daquelas populações, nem que se mantenha ao longo do tempo. Serão necessários estudos subsequentes para avaliar se estas competências foram incorporadas à prática profissional.

Os achados deste estudo, ao ressaltarem a centralidade do componente psicossocial na clínica da Atenção Primária, fazem coro tanto à crítica da noção de competência como ao desfecho mensurável e desterritorializado, assim como à crítica do reducionismo tecnicista da competência cultural, quando desconectada das necessidades reais dos usuários ${ }^{24}$, em especial quando se trata de encontro entre pessoas de universos sociais tão díspares. Para além da competência, o conceito de humildade cultural $^{40}$ pode informar as práticas educacionais em cenários comunitários, ajudando a formar médicos identificados e comprometidos com setores desassistidos e com a redução das desigualdades no acesso aos serviços de saúde. 


\section{Colaboradores}

FM Cardoso e GWS Campos tiveram participação na concepção, na análise, na redação e na revisão do texto.

\section{Referências}

1. Declaração de Alma-Ata. In: Conferência Internacional sobre Cuidados Primários de Saúde; 1978; Alma Ata, Cazaquistão. [Internet]. 1978 [cited 2019 Mar 03]. Available from: https://www.opas.org.br/declaracao-de-alma-ata/

2. Comes Y, Díaz-Bermúdez XP, Pereira LL, Oliveira FP, Caballero González JE, Shimizu HE, Santos LMP. Humanismo en la práctica de médicos cooperantes cubanos en Brasil: narrativas de equipos de atención básica. Rev Panam Salud Publica 2017; 41:e130.

3. Ceccim RB, Pinto LF A formação e especialização de profissionais de saúde e a necessidade política de enfrentar as desigualdades sociais e regionais. Rev Bras Educ Med 2007; 31(3):266-277.

4. Penfold R, Ali M. Building medical education and research capacity in areas of conflict and instability: experiences of the OxPal Medlink in the occupied Palestinian territories. Med Confl Surviv 2017; 30(3):166-174.

5. Scheffer M, organizador. Demografia médica no Brasil 2018. São Paulo: Departamento de Medicina Preventiva da Faculdade de Medicina da USP, Conselho Regional de Medicina do Estado de São Paulo, Conselho Federal de Medicina; 2018.

6. Brasil. Ministério da Educação, Conselho Nacional de Educação, Câmara de Educação Superior. Resolução $\mathrm{n}^{\circ}$ 3, de 20 de junho de 2014. Institui Diretrizes Curriculares Nacionais do Curso de Graduação em Medicina e dá outras providências. Diário Oficial da União 2014; 23 jun.

7. Vieira SP, Pierantoni CR Magnago C, Ney MS, Miranda RG. A graduação em medicina no Brasil ante os desafios da formação para a Atenção Primária à Saúde. Saúde Debate [Internet]. 2018 [cited 2019 Mar 03];42(Esp.1):189-207. Available from: http:// www.scielo.br/scielo.php?script=sci_arttext\&pid= S0103-11042018000500189\&lng=en\&nrm=iso\&tln$\mathrm{g}=\mathrm{pt}$

8. Rubenstein W, Talbot Y. Medical teaching in ambulatory care. Toronto: University of Toronto Press; 2013.

9. Bollela VR, organizador. Educação baseada na comunidade para as profissões da saúde: aprendendo com a experiência brasileira. Ribeirão Preto: FUNPEC - Editora; 2014.

10. Schrewe B, Ellaway R, Watling C, Bates J. The Contextual Curriculum: Learning In the Matrix, Learning From the Matrix. Acad Med 2018; 93:1.

11. Hodges BD, Lingard L. The question of competence: reconsidering medical education in the twentieth-first century. Ithaca: Cornell University Press; 2012.

12. Spencer J, Mckimm J. Patient involvement in medical education. In: Swanwick T, organizador. Understanding medical education: evidence, theory, and practice. Chichester: John Wiley \& Sons; 2014. p. 227-239.

13. Benbassat J. Hypothesis: the hospital learning environment impedes students' acquisition of reflectivity and medical professionalism. Adv Health Sci Educ Theory Pract 2019; 24(1):185-194.

14. Luz MT. Cultura contemporânea e medicinas alternativas: novos paradigmas em saúde no fim do século XX. Physis 1997; 7(1):13-43.

15. Campos GWS. A clínica do sujeito: por uma clínica reformulada e ampliada [mimeo]. Campinas: DMPS -UNICAMP; 1997. 
16. Foucault M. Crise da medicina ou da antimedicina. Verve 2010; 18:167-194.

17. Tesser CD. A verdade na biomedicina, reações adversas e efeitos colaterais: uma reflexão introdutória. Physis 2007; 17(3):465-484.

18. Merhy EE. A perda da dimensão cuidadora na produção da saúde: uma discussão do modelo assistencial e da intervenção no seu modo de trabalhar a assistência In: Franco TB, Merhy EE, organizadores. Trabalho, produção do cuidado e subjetividade em saúde: textos reunidos. São Paulo: Hucitec; 2013. p. 68-94.

19. Mcwhinney IR, Freeman T. Manual de medicina de família e comunidade. Porto Alegre: Artmed; 2010.

20. Bleakley A. Medical humanities and medical education: how the medical humanities can shape better doctors. London: Routledge; 2015.

21. Kleinman A, Eisenberg L, Good B. Culture, illness and care clinical lessons from anthropologic and crosscultural research. Ann Int Med 1978; 88:2.

22. Farmer PE, Nizeye B, Stulac S, Keshavjee S. Structural violence and clinical medicine. PLoS Med 2006; 3(10):e449.

23. Starfield B. Atenção Primária: equilíbrio entre necessidades de saúde, serviços e tecnologia. Brasília: UNESCO, Ministério da Saúde (MS); 2002.

24. Kleinman A, Benson P. Anthropology in the clinic: the problem of cultural competency and how to fix it. PLoS Med 2006; 3(10):e294.

25. Carraccio CL, Englander R. From flexner to competencies: reflections on a decade and the journey ahead. Acad Med 2013; 88:1067-1073.

26. Yardley S, Teunissen PW, Dornan T. Experiential learning: AMEE Guide No. 63. Med Teach 2012; 34(2):e102-e115.

27. Mann K, Mcleod A. Constructivism: learning theories and approaches to research. In: Cleland J, Durning S, organizadores. Researching medical education. Chichester: John Wiley \& Sons; 2015.

28. Kleinman A. "Everything that really matters": social suffering, subjectivity, and the remaking of human experience in a disordering world. Harv Theol Rev 1997; 90:315-336

29. Universidade Federal do Rio de Janeiro (UFRJ). Faculdade de Medicina. Internato Integrado em Medicina de Família e Comunidade e Saúde Mental. Rio de Janeiro: UFRJ; 2017.

30. Soranz D, Pinto LF, Penna GO. Eixos e a reforma dos cuidados em Atenção Primária em Saúde (RCAPS) na cidade do Rio de Janeiro, Brasil. Cien Saude Colet 2016; 21(5):1327-1338.
31. Williams A, Katz L. The use of focus group methodology in education: some theoretical and practical considerations. Int Electron J Leadersh Learn 2001; 5:3.

32. Minayo MCS Hermenêutica-dialética como caminho do pensamento social In: Minayo MCS, Deslandes SF, organizadores. Caminhos do pensamento: epistemologia e método. Rio de Janeiro: Editora Fiocruz; 2002. p. 337.

33. Bonet O. Os médicos da pessoa: um olhar antropológico sobre a medicina de família no Brasil e na Argentina. Rio de Janeiro: 7Letras; 2014

34. Foucault M. O nascimento da clínica. $6^{\mathrm{a}}$ ed. Rio de Janeiro: Forense Universitária; 2006.

35. Silva DAJ, Tavares MFL. Ação intersetorial: potencialidades e dificuldades do trabalho em equipes da Estratégia Saúde da Família na cidade do Rio de Janeiro. Saúde Debate 2016; 40(111):193-205.

36. Minayo MCS, Souza ER. Violência e saúde como um campo interdisciplinar e de ação coletiva. Hist Cien Saude Manguinhos 1997; 4(3):513-531.

37. Comitê Internacional da Cruz Vermelha (CICV). Acesso mais seguro para serviços públicos essenciais - relatório. Brasília: CICV; 2018.

38. Carvalho SR, Andrade HS, Cunha GT, Armstrong D. Paradigmas médicos e Atenção Primária à Saúde: vigilância da população e/ou produção de vida? Interface (Botucatu) 2016; 20(58):531-535.

39. Lancetti A. Clínica peripatética. São Paulo: Hucitec; 2008.

40. Foronda C, Baptiste D, Reinholdt MM, Ousman K. Cultural humility: a concept analysis. J Transcult Nurs 2016; 27(3):210-217.

Artigo apresentado em 16/04/2019

Aprovado em 17/05/2019

Versão final apresentada em 19/05/2019 